Article

\title{
A New Adjustment Strategy to Relieve Inhibition during Anaerobic Codigestion of Food Waste and Cow Manure
}

\author{
Guangxin Ren ${ }^{1,2, * \mathbb{D}}$, Chunlan Mao ${ }^{3}$, Ningning Zhai ${ }^{1,2}$, Boran Wang ${ }^{1,2}$, Zhichao Liu ${ }^{4}$, \\ Xiaojiao Wang ${ }^{1,2}$ and Gaihe Yang ${ }^{1,2}$ \\ 1 College of Agronomy, Northwest A\&F University, Yangling 712100, Shaanxi, China; \\ zhainingn@nwsuaf.edu.cn (N.Z.); a1227973223@nwsuaf.edu.cn (B.W.); w-xj@nwsuaf.edu.cn (X.W.); \\ ygh@nwsuaf.edu.cn (G.Y.) \\ 2 The Research Center of Recycle Agricultural Engineering and Technology of Shaanxi Province, \\ Yangling 712100, Shaanxi, China \\ 3 School of Life Sciences, LanZhou University, LanZhou 730000, China; maocl@lzu.edu.cn \\ 4 Yan'an meteorological bureau, Shaanxi Province, Yan'an 716000, Shaanxi, China; liuzhichao781017@163.com \\ * Correspondence: rengx@nwsuaf.edu.cn
}

Received: 29 March 2019; Accepted: 14 May 2019; Published: 17 May 2019

check for updates

\begin{abstract}
A new adjustment strategy (controlling temperature, $\mathrm{pH}$, inoculum dose, and liquid supernatant replacement in different digestion stages) was used to relieve volatile fatty acid (VFA) inhibition during anaerobic codigestion of FW and CM. Three digestion stages and groups were designed: initial stage (on days 1-5 the temperature was $45^{\circ} \mathrm{C}$ ), the second stage (on days 6-10 the temperature was $35^{\circ} \mathrm{C}$ and inoculum was supplied), and the third stage (on days 11-50 the temperature was $35{ }^{\circ} \mathrm{C}$ and liquid supernatant was replaced). Groups $\mathrm{A}, \mathrm{B}$, and C had initial inoculums of 0,100 , and $200 \mathrm{~mL}$ and were supplied inoculums of 200, 100, and $0 \mathrm{~mL}$, respectively. Results showed that in the initial stage, Group A had the highest VFA concentration $(876.54 \mathrm{mg} / \mathrm{L})$ and the lowest $\mathrm{pH}(3.6)$. In the second and third stages, $\mathrm{pH}(\sim 5.5$ and $~ 7.5)$ and VFA concentrations showed no significant differences in all groups. The highest VFA concentration $(3248 \mathrm{mg} / \mathrm{L})$, volatile solid (VS) removal rate (49.72\%), and total methane production (TMP) $(10,959 \mathrm{~mL})$, the shortest $\lambda$ (19.92 d), and the $\mathrm{T}_{90 \%}$ (39.25 d) were obtained in Group B (pH 8.5). Group C had the highest chemical oxygen demand (COD) removal rate (96.91\%). Group A obtained the maximal TBP of 25,626 mL ( $\mathrm{pH} 8.0)$.
\end{abstract}

Keywords: anaerobic co-digestion; operational conditions; adjusting strategy; food waste; cow manure

\section{Introduction}

About 2.2 billion tons of food waste (FW) will be generated in the world by 2025, and total food loss will be about 310 billion tons in developing countries (like China) [1]. Therefore, FW pollution has gradually become a global problem [2]. It is worth noting that FW contains rich organic matter (35.5\%-69\% sugar and $4 \%-22 \%$ protein) [3,4], high moisture content $(74 \%-90 \%)$, and low $\mathrm{pH}$, and is more biodegradable than other organic wastes. So, FW has been regarded as the most promising anaerobic substrate [2] and has great potential for methane production.

However, the inhibition process caused by volatile fatty acid (VFA) accumulation is a common phenomenon for anaerobic digestion (AD) of FW [5-9], which inhibits the growth of microorganisms [10] and the digestion process. Anaerobic codigestion of FW with other wastes, such as piggery wastewater [11], wastewater, sewage sludge, green waste [4], and cow manure (CM) [9], could balance 
system stablity by offering toxicity dilution, synergism, divers, a robust microbiome, etc. [1,4,12]. Biogas production compared to different digestion conditions is summarized in Table 1.

Table 1. Summary of anaerobic digestion (AD) and biogas/methane yield of food waste (FW).

\begin{tabular}{|c|c|c|}
\hline Substrate & Operational Conditions & Biogas/Methane Yield \\
\hline $\mathrm{FW}+\mathrm{CM}^{\mathrm{a}}$ & $\begin{array}{l}\text { One stage model, dry } \mathrm{AD} \text {, total solid (TS), } \\
\text { substrate ratio, } 55^{\circ} \mathrm{C} \text { pretreatment }\end{array}$ & $\begin{array}{l}\text { Methane yield of } 0.43 \mathrm{~m}^{3} \mathrm{CH}_{4} / \mathrm{kg} \text { volatile solid } \\
\text { (VS) reduced (TS 30\%+pretreatment) [3] }\end{array}$ \\
\hline FW & One stage model, monodigestion under $37^{\circ} \mathrm{C}$ & Specific methane yield of $683 \mathrm{~mL} \mathrm{~g}^{-1} \mathrm{VS}_{\text {added }}$ [5] \\
\hline $\mathrm{FW}+\mathrm{PM}^{\mathrm{b}}+\mathrm{RS}^{\mathrm{c}}$ & $\begin{array}{c}\text { Two stage model, codigestion with a mixture } \\
\text { ratio } 0.4: 1.6: 1,37^{\circ} \mathrm{C}\end{array}$ & Biogas yield of $674.4 \mathrm{~L} / \mathrm{kg}$ VS [10] \\
\hline FW & $\begin{array}{l}\text { Three stage model, monodigestion, } \mathrm{HRT}^{\mathrm{d}} \text { of } \\
12 \text { days, thermophilic }\left(55^{\circ} \mathrm{C}\right)\end{array}$ & Methane yield of $223 \mathrm{LCH}_{4} / \mathrm{kg} \mathrm{sCOD}$ degraded [10] \\
\hline $\mathrm{FW}+\mathrm{CM}$ & One stage model, initial $\mathrm{pH} 7.5,35^{\circ} \mathrm{C}$ & Methane yield of $8579 \mathrm{~mL}[9]$ \\
\hline FW+PM & Semicontinuous model, codigestion, $37^{\circ} \mathrm{C}$ & Methane yield of $0.396 \mathrm{~m}^{3} / \mathrm{kg} \mathrm{VS}_{\text {added }}$ [11] \\
\hline $\mathrm{FW}+\mathrm{TA}^{\mathrm{e}}$ & One stage model, codigestion, C:N $15: 1,55^{\circ} \mathrm{C}$ & Biogas yield of $388.6 \mathrm{~mL} / \mathrm{g}$ TS [12] \\
\hline FW & $\begin{array}{l}\text { One stage model, monodigestion, feed to } \\
\text { inoculum ratio of } 1: 2,37^{\circ} \mathrm{C}\end{array}$ & Methane yield of 627 mL/g VS [13] \\
\hline
\end{tabular}

On the other hand, to ease VFA tocxity many inhibitors have been controlled such as temperature [5], C:N ratio [4], hydraulic retention time [10], substrate to inoculum ratio (SIR) [1], $\mathrm{pH}$ [9], and substrate ratio [3]. This proved that controlling temperature, SIR, and $\mathrm{pH}$ were more effective methods. The solution was that these studies focused on controlling these factors at the initial stage of AD; however, AD process can be divided into four stages: hydrolysis, acidogenesis, acetogenesis, and methanogenesis [14]. So, adjusting these factors at different stages might efficiently ease VFA tocxity.

In the present study, we attempted to control these factors (temperature, SIR, and $\mathrm{pH}$ ) in different digestion stages to ease VFA tocxity. Several studies proved that an optimum SIR can effectively decrease the digestion period, offer approriate microbes, accelerate startup, and buffer the capacity of the system, thus significantly improving methane prodcution [1]. It will be controlled during hydrolysis and acidogenesis stages by adding different doses of inoculum. Optimum conditions accelerate the metabolic rate and alter the hydrolysis kinetics and solubility of the substrate [1]. Thermophilic conditions can enhance the hydrolysis of $\mathrm{FW}$, though the organic conversion rate to methane is slower [1,15]. Mesophilic conditions are more stable for methane production [16]. So, thermophilic conditions will be investigated during hydrolysis and acidogenesis stages, while mesophilic conditions will be investigated during acetogenesis and methanogenesis stages. $\mathrm{pH}$ has an important influence on the $\mathrm{AD}$ system, and it is the key control factor because there are different optimum $\mathrm{pH}$ ranges for microoganisms $[2,16,17]$. The optimum $\mathrm{pH}$ range for hydrolysis and acidogenic microoganisms is 5.5-6.5 [18]. FW digestion decreases system $\mathrm{pH}$ (3.6-4.5 in this study), which could meet the $\mathrm{pH}$ level for hydrolysis and acidogenic microoganisms. Thus, in the intial stage, it would not be necessary to adjust $\mathrm{pH}$. However, the optimal $\mathrm{pH}$ for methanogens is about $7.0[1,16]$. Thus, $\mathrm{pH}$ adjustment after acidogenesis is essential. In additon, liquid supernate replacement using fresh inoculum when no biogas is produced (methanogenesis stage) could ease VFA tocxity, though no studies have been done in this area; this will be investigated in the present study. Considering these controlling methods, we named this strategy as a new adjusting strategy to relieve the inhibition process caused by VFA accumulation in anaerobic codigestion of FW and CM.

Kinetics have been widely used to reflect digestion characteristics during the anaerobic digestion process and to predict the digestion potential and microbial activity. The modified Gompertz model is an important kinetic model to assess the ability of microorganisms to adapt to anaerobic reaction conditions, evaluate digestion time, and predict the biogas production rate potential. Thus, it has been widely used in the anaerobic digestion process $[13,19]$ and in the digestion of FW $[1,12,20]$. So, it was 
also used to further represent digestion efficiency and to assess digestion time and potential in the present study.

We hypothesized that adjusting inoculum additions, temperature, $\mathrm{pH}$, and supernatant liquid replacement at different digestion stages would significantly improve the codigestion efficiency of FW and CM. Therefore, in the present study, we focused on (1) the effects of adjusting these factors at different digestion stages on the performance and biogas/methane production of FW, and (2) optimizing the adjusting strategy for improving AD efficiency of FW. To evaluate these points, organic biodegradation, process stability, biogas/methane production, and kinetic characteristics were investigated.

\section{Materials and Methods}

\subsection{Feedstock and Inoculum}

FW was collected from a canteen at Northwest A\&F University, Yangling, China. Before the batch experiments, $\mathrm{FW}$ was ground into $5 \mathrm{~mm}$ pieces using a food grinder to ensure homogeneity, and then it was stored at $4{ }^{\circ} \mathrm{C}$. The fresh $\mathrm{CM}$ was collected from a local village in Yangling, China. The digestion inoculum was obtained from a well-digested household biogas digester in the same village. The main characteristics (average data plus standard errors in duplicate tests) of FW, CM, and inoculum are shown in Table 2. FW was characterized by high volatile solid (VS) content $(94.48 \%$, total solid (TS) basis), which indicated rich, biodegradable organic content. However, the $\mathrm{pH}$ value (5.3) was much lower than CM (7.3) and the inoculum (7.8); therefore, acid inhibition easily occurred during the anaerobic digestion process and, consequently, influenced digestion performance. Neutral $\mathrm{pH}$ values of 7.3 and 7.8 were found for $\mathrm{CM}$ and the inoculum, respectively, which were helpful for balancing the $\mathrm{pH}$ level and improving the self-buffering capacity of the codigestion system with FW. Thus anaerobic codigestion of FW and CM was essential.

Table 2. Characteristics of food waste (FW), cow manure (CM), and inoculum.

\begin{tabular}{|c|c|c|c|c|c|c|}
\hline & TS (\%) ${ }^{a}$ & VS (\%) ${ }^{a}$ & $\mathrm{pH}$ & $C(\%)^{b}$ & $N(\%)^{b}$ & C:N \\
\hline FW & $29.55 \pm 2.77$ & $94.48 \pm 0.08$ & $5.3 \pm 0.05$ & $44.41 \pm 3.12$ & $1.43 \pm 0.16$ & $31.10 \pm 1.35$ \\
\hline $\mathrm{CM}$ & $22.16 \pm 1.50$ & $54.08 \pm 3.46$ & $7.3 \pm 0.02$ & $36.25 \pm 2.98$ & $1.58 \pm 0.23$ & $22.96 \pm 0.66$ \\
\hline Inoculum & $5.29 \pm 0.45$ & $46.73 \pm 1.03$ & $7.8 \pm 0.11$ & $23.38 \pm 0.54$ & $1.68 \pm 0.09$ & $13.92 \pm 0.22$ \\
\hline
\end{tabular}

Note: TS, total solid; VS, volatile solid; C, total organic carbon; N, total Kjeldahl nitrogen; ${ }^{\text {a }}$ based on dry matter;

$\mathrm{b}$ based on TS.

\subsection{Anaerobic Digestion ( $A D)$ Experiments}

A laboratory-scale AD system was used for all experiments as described in [19]. FW and CM were used as cosubstrates with a mixing ratio of 1:1 (wet weight basis). The total digester volume was $1 \mathrm{~L}$ with $700 \mathrm{~mL}$ working volume, including the total inoculum and substrate. According to the daily biogas production rate, all experimental periods $(50 \mathrm{~d})$ were divided into three different stages as follows:

The initial stage: the digestion duration was 1-5 d. The first daily biogas production peak was obtained on the fifth day, the digestion temperature was controlled at $45{ }^{\circ} \mathrm{C}$ to enhance the biodegradation rate of the substrate, which has been proven to be an optimal temperature for FW biodegradation [14].

The second stage: the digestion duration was 6-10 d. The second daily biogas production peak was obtained on the 10 th day, the digestion temperature was controlled at $35^{\circ} \mathrm{C}$, which was more suitable for microbial activity and process stability [21], and the $\mathrm{pH}$ value of all experiments was adjusted to $7.0,7.5,8.0$, and 8.5 using $4.5 \mathrm{~mol} / \mathrm{L} \mathrm{Ca}(\mathrm{OH})_{2}$.

The third stage: the digestion duration was $11-50 \mathrm{~d}$. Daily biogas was produced steadily after the 10th day, the digestion temperature was controlled at $35^{\circ} \mathrm{C}$, and the $200 \mathrm{~mL}$ supernatant of digestion liquid was replaced by $200 \mathrm{~mL}$ fresh inoculum, once no biogas was produced, until the end of the experiment. This could thoroughly relieve organic acid inhibition in the digestion process. 
Furthermore, to clearly investigate the effects of these operational conditions, three experimental groups were determined, namely Group A, Group B, and Group C, based on the inoculum dose and addition time.

Group A: in the initial stage, no inoculum was added. In the second stage, $200 \mathrm{~mL}$ inoculum was supplied. In the third stage, no inoculum was added.

Group B: in the initial stage, $100 \mathrm{~mL}$ inoculum was added. In the second stage, $100 \mathrm{~mL}$ inoculum was supplied. In the third stage, no inoculum was added.

Group C: in the initial stage, $200 \mathrm{~mL}$ inoculum was added. In the second stage and the third stage, no inoculum was supplied. Detailed information on the experimental design is shown in Table 3.

Table 3. Detailed information on the experimental design.

\begin{tabular}{|c|c|c|c|c|c|}
\hline Stages & $\begin{array}{l}\text { Operational } \\
\text { Conditions }\end{array}$ & Group A & Group B & Group C & Temperature $\left({ }^{\circ} \mathrm{C}\right)$ \\
\hline \multirow{4}{*}{$\begin{array}{l}\text { The initial stage } \\
\text { (on days 1-5) }\end{array}$} & FW & $108.3 \mathrm{~g}$ & $108.3 \mathrm{~g}$ & $108.3 \mathrm{~g}$ & \multirow{4}{*}{$45^{\circ} \mathrm{C}$} \\
\hline & $\mathrm{CM}$ & $108.3 \mathrm{~g}$ & $108.3 \mathrm{~g}$ & $108.3 \mathrm{~g}$ & \\
\hline & Water & $283.4 \mathrm{~mL}$ & $283.4 \mathrm{~mL}$ & $283.4 \mathrm{~mL}$ & \\
\hline & Initial Inoculum & $0 \mathrm{~mL}$ & $100 \mathrm{~mL}$ & $200 \mathrm{~mL}$ & \\
\hline \multirow{2}{*}{$\begin{array}{l}\text { The second stage } \\
\text { (on days 6-10) }\end{array}$} & Inoculum supplied & $200 \mathrm{~mL}$ & $100 \mathrm{~mL}$ & $0 \mathrm{~mL}$ & \multirow{2}{*}{$35^{\circ} \mathrm{C}$} \\
\hline & $\mathrm{pH}$ adjustment & \multicolumn{3}{|c|}{$7.0,7.5,8.0,8.5$} & \\
\hline $\begin{array}{l}\text { The third stage } \\
\text { (on days 11-50) }\end{array}$ & $\begin{array}{l}\text { Supernatant liquid } \\
\text { replacement }\end{array}$ & \multicolumn{3}{|c|}{$\begin{array}{l}200 \mathrm{~mL} \text { fresh inoculum replaced } 200 \mathrm{~mL} \\
\text { supernatant liquid if no biogas was produced }\end{array}$} & \\
\hline
\end{tabular}

The TS content of each digester was $8 \%$ according to our previous studies, in which TS $=8 \%$ proved to be an optimum value for $\mathrm{AD}$ performance [22,23]. All experiments were conducted in triplicate.

\subsection{Kinetic Model}

The duration of the lag phase $(\lambda)$ was predicted by the modified Gompertz model (MGE) according to a previous study [22], shown as Equation (1). Accordingly, the digestion period ( $\mathrm{T}_{100 \%}$, the time to produce the total biogas production, TBP) was also predicted.

$$
M_{(t)}=P \cdot \exp \left\{-\exp \left[\frac{R_{m} \cdot e}{P}(\lambda-t)+1\right]\right\}
$$

where $M_{(t)}$ is the accumulative biogas production $(\mathrm{mL})$ at an anaerobic digestion time $t(\mathrm{~d}), P$ is the biogas production potential $(\mathrm{mL}), R_{m}$ is the maximum biogas production rate $(\mathrm{mL}), \lambda$ is the duration of lag phase (d), and $e=2.7183$.

\subsection{Analytical Methods}

TS, VS, C, N, and VFAs were determined according to the standard methods of the American Public Health Association (APHA, 1998). Chemical oxygen demand (COD) was analyzed by Multi-Parameter Testers (ET99718). Daily biogas production was measured using a water displacement method. A biogas analyzer (Gasboard-3200p) was used to analyze the methane content in biogas and $\mathrm{pH}$ value during the digestion process. The $\mathrm{pH}$ value and VFA concentration were determined every five days, and the methane content was measured every day.

\subsection{Statistical Analyses}

To test for differences in biogas/methane production and process parameters ( $\mathrm{pH}, \mathrm{VFAs}, \mathrm{VS}$, and COD removal rate) of each treatment in relation to operational conditions, one-way ANOVA and Duncan's multiple range test (DMRT) were used to analyze variance of means using SPSS 20.0. $\lambda$ was calculated by fitting the kinetic model based on accumulated biogas production using SPSS 20.0. 


\section{Results and Discussion}

\subsection{Biogas Production and Methane Content}

\subsubsection{Effect of Initial Inoculum Addition on Biogas and Methane Production}

Daily biogas production and methane content of each group with different inoculum doses are shown in Figure 1. In the initial stage, daily biogas production in all groups rapidly increased. For Groups A (Figure 1A) and B (Figure 1B), the first biogas production peak appeared after the first two days, and it decreased sharply to zero after the third day. For Group C, the first biogas production peak was achieved on the fourth day. The main reason could be the different SIR ratios. Previous studies proved that SIR was one important factor that influenced biogas production, especially for FW [1,24]. When the SIR $<2$, digesters operated efficiently with a high methane recovery rate [1,24]. In the initial stage, the SIRs of Group B and Group C were 2.17 and 1.08, respectively. For Group A, no inoculum was added; therefore, the time to obtain the first daily biogas production peak was delayed for Group C. However, the methane content was almost zero for all experiments, as shown in Figure 1. This was similar to the results from a previous study [10] in which rapid, increased daily biogas production was achieved on the first day with a low methane concentration (18.7\%) and a high $\mathrm{CO}_{2}$ concentration (67.4\%). The main reason was acidogenesis during this period [10,25]. Additionally, $45^{\circ} \mathrm{C}$ accelerated the acidification of the substrate caused by faster reaction rates than the mesophilic temperatures of approximately $35{ }^{\circ} \mathrm{C}$ [14]. Furthermore, the rapidly decreased pH value (shown in Figure 2) also indicated acidogenesis in the initial stage. As a result, initial inoculum additions showed no significant influences on biogas/methane production in the initial stage. Compared to the total biogas production (TBP) in this period, the highest average value of $2535 \mathrm{~mL}$ was obtained from Group C, which was significantly higher than Group B $(44.8 \%)$ and Group C (53\%) $(p<0.05)$. This could be thoroughly explained by the suitable SIR in Group C; however, each substrate had its own optimum SIR ratio, and, consequently, the results of each study were different.

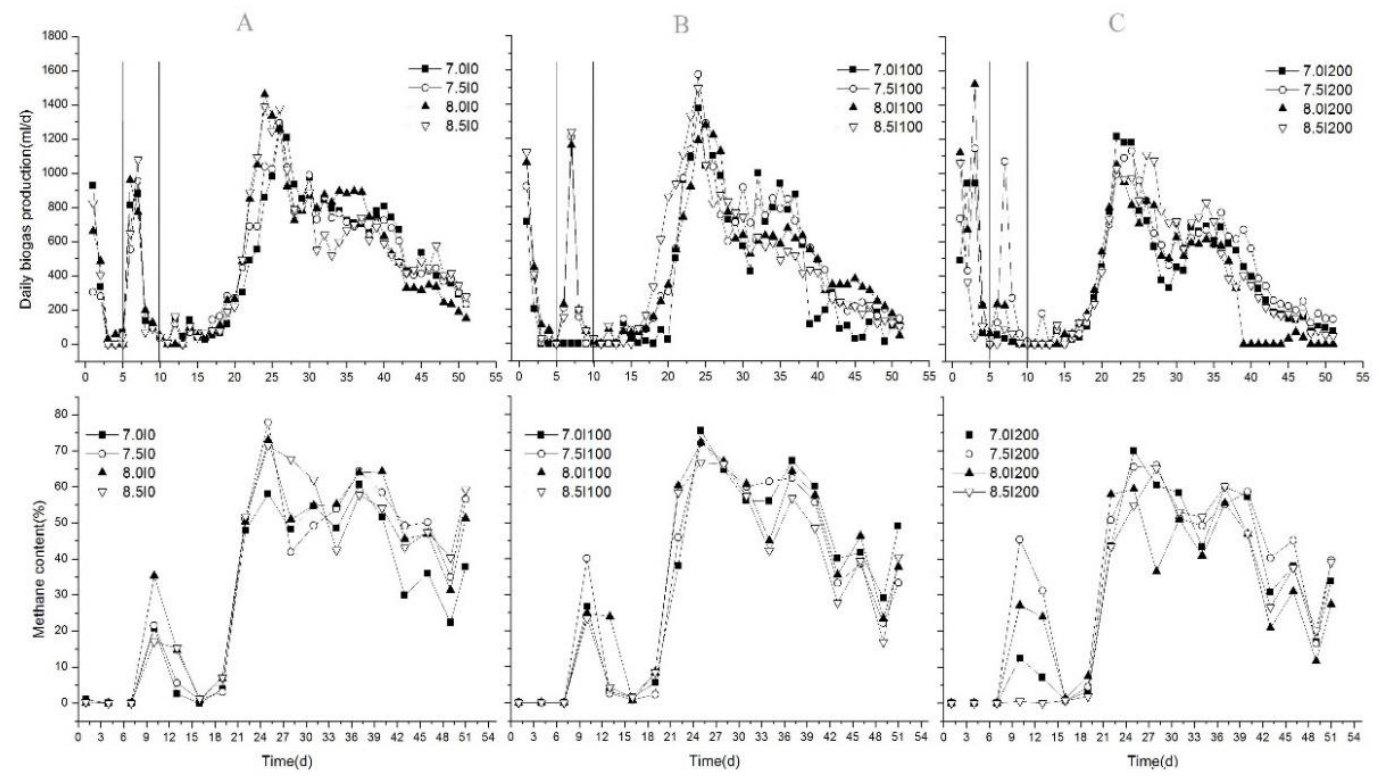

Figure 1. Variations in daily biogas production and methane content. A, group A, B, group B, C, group $\mathrm{C}$

\subsubsection{Effects of Inoculum Supplement and pH Adjustment on Biogas/Methane Production}

In the second stage, each sample held the same amount of inoculum after adding the rest of the inoculum into Groups A and B to achieve a total volume of $200 \mathrm{~mL}$. Then, the $\mathrm{pH}$ was adjusted to 7.0, 7.5, 8.0, and 8.5. From Figure 1, shows that biogas generation rapidly recovered and peaked on 
the seventh day for each treatment, and then it decreased rapidly along with the methane content. The order of the peak value was B $(1210 \mathrm{~mL} / \mathrm{d})>\mathrm{C}(1017 \mathrm{~mL} / \mathrm{d})>\mathrm{A}(955 \mathrm{~mL} / \mathrm{d})$. Maximal TBPs were obtained at pH $7.5(2330 \mathrm{~mL}), 8.5(2136 \mathrm{~mL})$, and $8.0(1728 \mathrm{~mL})$ for Groups B, A, and C, respectively. Although maximal TBP was obtained in Group C in the initial stage, it was obtained in Group B in the second stage. Therefore, we hypothesized that low inoculum additions (100 $\mathrm{mL}$ in Group B) in both stages could be an alternative method to improve biogas production. No inoculum addition $(0 \mathrm{~mL}$ in Group A) or high inoculum addition $(200 \mathrm{~mL}$ in Group C) in the initial stage could both result in deterioration. Biogas generation in Groups A and B during these days could be affected by both the supply of microbes and the change of alkalinity in the digestion system; the microbe activities were different in Groups A and B. For Group A, inoculum was added until the sixth day, and the microbial population was the least, which was only supplied by the cosubstrate. Although inoculum was supplied up to $200 \mathrm{~mL}$, a lower $\mathrm{pH}$ and buffer capacity could result in a delayed recovery process, so a higher $\mathrm{pH}$ was needed. As a result, the maximum TBP was achieved when $\mathrm{pH}$ was adjusted to 8.5 for Group A. We also found that a slight alkali pH (> 7.0) adjustment when the $\mathrm{pH}$ value of the AD system dropped to a very low level (3.6-4.5 (Figure 2) in the present study) could be suitable for anaerobic codigestion of FW and CM, which could improve the self-buffering capacity and recovery process of the system. These findings were different from the results obtained from [10], in which a higher biogas production was found at $\mathrm{pH} 7.0$ using $\mathrm{NaHCO}_{3}$ and $\mathrm{NaOH}$ adjustments. Zhou [26] also found that neutral $\mathrm{pH}$ control (6.8-7.2) in the AD process of pig manure improved biogas production. The main reason could be the differences in the substrate.

\subsubsection{Effect of Supernatant Liquid Replacement on Biogas/Methane Production}

At the end of the second stage, biogas production of all treatments dropped significantly by the 10th day, and almost no biogas was produced by the 11th day (Figure 1), which could correspond to the maximum VFA concentration; however, after replacing the supernatant liquid using the same volume of fresh inoculum, biogas production increased slowly until achieving the peak value. Thus, in the third stage, daily biogas production and methane content increased steadily. However, no similar study was done, except for our present study. On the one hand, fresh inoculum enhanced the consumption of VFAs to generate biogas by supplementing microorganisms, and the inhibition of VFAs was relieved. On the other hand, it reduced VFA concentrations directly, which also relieved the inhibition of VFAs. For methane production, in the early stages of rising biogas production, biogas production rose rapidly to the maximum value, which indicated abundant methanogens in the new inoculum. Thereafter, methane content decreased with little fluctuation. Ignoring the effects of $\mathrm{pH}$, the average methane contents were $40.4 \%, 40.4 \%$, and $35.9 \%$ for Groups A, B, and C, respectively, while maximum methane contents were obtained at $\mathrm{pH}$ adjustments of 8.0, 8.0, and 7.5 in Groups A, B, and C, respectively. The average methane content ranged from $36 \%$ to $41 \%$, which was lower than $58.7 \%-61.8 \%$ obtained from the previous study [27]. The reason was the higher FW content in the substrate in this study $(50 \%)$ compared to $32 \%$ and $48 \%$ in [27]; thus, the inhibition process was caused by VFAs [10]. Additionally, removal of supernatant liquid could reduce VFA content directly, thereby decreasing biogas/methane production. So, it was important that the supernatant liquid was replaced using fresh inoculum to recover the AD process. These results were different with the results of [10], in which the AD process was inhibited when the FW content in the substrate increased. Above all, this kind of adjusting strategy could improve biogas/methane production effectively.

\subsection{Variations of $\mathrm{pH}$ and Volatile Fatty Acids (VFAs)}

\subsubsection{Effect of Initial Inoculum Addition on $\mathrm{pH}$ and VFAs}

VFA concentration and $\mathrm{pH}$ level during anaerobic digestion of FW have been widely used as an indicator of stability and self-buffering capacity $[3,28,29]$. Variations in $\mathrm{pH}$ and VFA concentration during the AD process at different stages are shown in Figure 2. Results revealed that, in the initial 
stage, Group C had the highest initial pH (6.4), followed by Group B (5.9), and then Group A (5.4). The main reason was the high inoculum dose in Group $\mathrm{C}$, which could balance the $\mathrm{pH}$ level of the AD system as a buffer agent [12]. Then, $\mathrm{pH}$ values of all treatments decreased to their lowest values as a result of the acidification of organic matter [30], which was analyzed in Section 3.1.1. The lowest $\mathrm{pH}$ values were $\mathrm{A}(3.6)<\mathrm{B}(3.8)<\mathrm{C}(4.5)$, which further illustrated the significant effects of different inoculum volumes. Therefore, $200 \mathrm{~mL}$ inoculum addition in Group $\mathrm{C}$ improved the self-buffering capacity in the initial stage. Also, although acidogenesis microorganisms can tolerate a wide $\mathrm{pH}$ range (4.0-8.5), the optimal $\mathrm{pH}$ range for hydrolysis and acidogenesis was 5.5-6.5; therefore, $\mathrm{pH}$ adjustment in the second stage was necessary and created a more favorable environment for the AD process.

VFAs are the important process indicators during the AD process, especially for FW. Numerous studies proved that accumulation of VFAs negatively affected $\mathrm{pH}$ [31], which resulted in process inhibition and consequent biogas production. Variations in VFA concentrations in all groups are shown in Figure 2. The initial concentrations of Groups B $(442.68 \mathrm{mg} / \mathrm{L})$ and C $(479.72 \mathrm{mg} / \mathrm{L})$ were significantly lower than that achieved in Group A $(876.54 \mathrm{mg} / \mathrm{L})(p<0.05)$. The reason might be that the consumption rate of VFAs producing biogas/methane was high in the former two groups. In this stage, VFA concentration rapidly increased as a result of hydrolysis and acidification. However, on the fifth day, VFA concentrations of Groups B and C were 2.29 and 2.32 times higher than Group A, respectively. This phenomenon showed that inoculum additions in the initial stage allowed a faster organic biodegradation rate and VFA production rate from the microorganism supply [13].

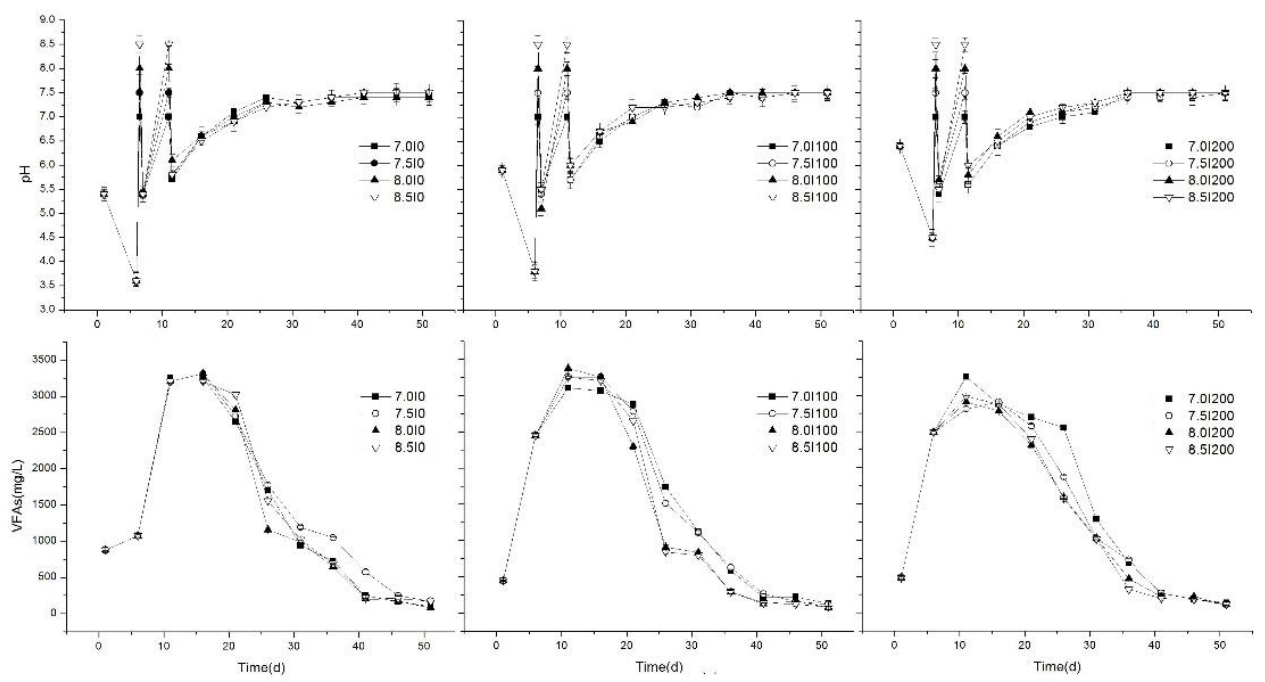

Figure 2. Variations of $\mathrm{pH}$ and VFA concentrations during the anaerobic digestion process.

\subsubsection{Effects of Inoculum Supply and $\mathrm{pH}$ Adjustment on $\mathrm{pH}$ and VFAs}

In the second stage, although the remaining inoculum was supplied and $\mathrm{pH}$ was adjusted to 7.0, $7.5,8.0$, and 8.5 for all groups, the $\mathrm{pH}$ decreased rapidly, and the average $\mathrm{pH}$ values of Groups $\mathrm{A}$, $B$, and $C$ were about $5.4,5.4$, and 5.5 , which was caused by a rapidly increased VFA concentration. However, along with $\mathrm{AD}$ progression, the $\mathrm{pH}$ of all treatments showed a slow increasing trend and rose to 7.0 on the 10th day. This was considered appropriate for the methanogenesis process [32], in which the optimum $\mathrm{pH}$ range of 6.5-8.2 for methanogenesis in the anaerobic digestion process was found. So, daily biogas/methane showed an obvious peak (Figure 1). Furthermore, no significant differences $(p>0.05)$ of $\mathrm{pH}$ between each group were found in this stage. The reason might be the similar adjustment strategy of $\mathrm{pH}$, while the inoculum supplement showed a significant effect on the $\mathrm{pH}$ of the $\mathrm{AD}$ system compared to $\mathrm{pH}$ adjustment.

VFA concentrations of all treatments reached maximal values on day 10 and 11 , and the maximal average VFA concentrations of Groups A, B, and C were 3209, 3248, and $2990 \mathrm{mg} / \mathrm{L}$, respectively. No significant differences were found, which further revealed similar stabilities indicated by $\mathrm{pH}$. 
This may be attributed to the supplied inoculum added to Groups A and B that provided more hydrolytic and acidification bacteria. However, significant differences $(p<0.05)$ were found after the $\mathrm{pH}$ was adjusted, and the maximal VFA concentration was obtained at $\mathrm{pH} 8.0$ in Group B $(3374 \mathrm{mg} / \mathrm{L})$. A previous study indicated that toxic effects caused by VFAs could be eased by increasing the consumption rate or the electrodigestion process. In this study, $\mathrm{pH}$ adjustment ensured an optimal $\mathrm{pH}$ level for methanogenesis, thus, the conversion rate of VFAs to biogas was enhanced. Differently, in our previous study [12], although the $\mathrm{pH}$ was adjusted at the initial stage, the VFA concentration was more than $3440 \mathrm{mg} / \mathrm{L}$ and caused inhibition. Contrarily, in the present study, the $\mathrm{pH}$ was adjusted after hydrolysis and acidification stages (initial stage), and a lower VFA was produced, which was preferable for biogas/methane production.

\subsubsection{Effect of Supernatant Liquid Replacement on $\mathrm{pH}$ and VFAs}

In the third stage, the $\mathrm{pH}$ variations of all treatments were similar after the supernatant was replaced. They all rose to $\sim 7.0$ after $10 \mathrm{~d}$, and reached their stable values of $\sim 7.5$ after $25 \mathrm{~d}$ (Figure 2 ). These final $\mathrm{pH}$ values were harmonious with the normal growth of anaerobic microorganisms [33]. With the recovery of biogas production, VFA concentrations of all treatments fell dramatically by day 15 as a result of methane conversion. The duration times of high VFA concentrations were shorter compared to the previous study [12], in which the VFA concentrations fell dramatically by day 30, and $\mathrm{pH}$ was only adjusted initially. Therefore, it could be speculated that in this stage, although VFA accumulation inhibited methane production, supernatant liquid replacement using fresh inoculum when no biogas was produced could efficiently ease VFA inhibition and create a stable environment for methanogens. Thus, the methane conversion rate of VFAs was improved, and the duration time of high VFAs decreased. This could be indicated by stable biogas/methane production and $\mathrm{pH}$ level. As the process of digestion continued, VFAs concentrations decreased slowly to $78-173 \mathrm{mg} / \mathrm{L}$ at the end of anaerobic digestion, which was in accordance with previous research [34,35]. The lowest VFA concentrations of Groups A, B, and C were obtained at pH $8.0(74 \mathrm{mg} / \mathrm{L}), 8.0(77 \mathrm{mg} / \mathrm{L})$, and 7.5 $(108 \mathrm{mg} / \mathrm{L})$, respectively, and the maximal reduction rate of VFA concentration was $97.7 \%$ at $\mathrm{pH} 8.0$ for Group B in the last 40 days, which was similar with TBP.

\subsection{Removal Rate of Volatile Solid (VS) and Soluble Chemical Oxygen Demand (COD)}

At the end of the AD process, the removal rates of VS and COD were investigated. It is well known that biogas/methane generation is accompanied by the degradation of organic components in substrates. Thus, reductions of VS and COD are useful parameters for evaluating the efficiency in AD [10,32]. As shown in Table 4, the average VS removal rates were $44.82 \%$ (Group B) $>40.90 \%$ (Group C) $>38.62 \%$ (Group A), which was similar with the TBP. The average VS removal rates for pH 7.0, 7.5, 8.0, and 8.5 were $39.11 \%, 40.13 \%, 42.98 \%$, and $43.85 \%$, respectively. It increased with an increased $\mathrm{pH}$ value. This can be explained as higher $\mathrm{pH}$ adjustments were beneficial in improving environmental conditions for microorganism digestion, so degradation of substrates was enhanced. The highest removal rate of VS was obtained at $\mathrm{pH} 8.5(49.72 \%)$ in Group B, which was lower than $54.01 \%$ as reported in [36]. The main reason would be the higher frequency of $\mathrm{pH}$ adjustments, which was proven by Li et al.[36].

The average removal rates of soluble COD for Groups A, B, and C were $92.64 \%, 93.46 \%$, and $96.91 \%$, respectively. It increased as the inoculum dose increased in initial stages, since the higher the inoculum dose, the earlier the substrate capacity was degraded. The average COD removal rates for $\mathrm{pH} 7.0,7.5$, 8.0 , and 8.5 were $93.12 \%, 92.34 \%, 96.33 \%$, and $88.88 \%$, respectively. Notably, $\mathrm{pH} 8.0$ was optimum for COD degradation. Therefore, considering all operational conditions, $\mathrm{pH}$ adjustment could be an efficient method for improving organic biodegradability and biogas production. 
Table 4. Degradation rate of VS and soluble chemical oxygen demand (COD).

\begin{tabular}{|c|c|c|c|}
\hline \multicolumn{4}{|c|}{ VS Degradation Rate (\%) } \\
\hline & Group A & Group B & Group C \\
\hline pH 7.0 & $38.49 \pm 0.53(\mathrm{AB})$ & $41.98 \pm 1.66(\mathrm{~B})$ & $36.82 \pm 1.24(\mathrm{~B})$ \\
\hline $\mathrm{pH} 7.5$ & $36.65 \pm 0.08(\mathrm{~B})$ & $42.58 \pm 2.02(\mathrm{~B})$ & $40.67 \pm 2.29(\mathrm{AB})$ \\
\hline pH 8.0 & $41.20 \pm 1.81(\mathrm{~A})$ & $45.12 \pm 0.24(\mathrm{AB})$ & $42.25 \pm 0.83(\mathrm{~A})$ \\
\hline $\mathrm{pH} 8.5$ & $38.12 \pm 1.43(\mathrm{AB})$ & $49.61 \pm 2.11(\mathrm{~A})$ & $43.84 \pm 1.26(\mathrm{~A})$ \\
\hline \multicolumn{4}{|c|}{ Soluble COD Degradation Rate (\%) } \\
\hline & Group A & Group B & Group C \\
\hline pH 7.0 & $88.58 \pm 0.55(\mathrm{~B})$ & $93.59 \pm 0.67(\mathrm{~A})$ & $97.18 \pm 0.29(\mathrm{~A})$ \\
\hline $\mathrm{pH} 7.5$ & $87.34 \pm 0.69(\mathrm{~B})$ & $94.16 \pm 0.58(\mathrm{~A})$ & $95.43 \pm 0.58(\mathrm{AB})$ \\
\hline $\mathrm{pH} 8.0$ & $99.13 \pm 0.15(\mathrm{~A})$ & $91.35 \pm 0.92(\mathrm{~A})$ & $98.12 \pm 0.73(\mathrm{~A})$ \\
\hline $\mathrm{pH} 8.5$ & $95.09 \pm 0.64(\mathrm{~A})$ & $75.25 \pm 0.79(\mathrm{~B})$ & $93.91 \pm 0.66(\mathrm{~B})$ \\
\hline
\end{tabular}

Note: Different capital letters in parentheses mean significant difference at 0.05 level.

\subsection{Total Biogas and Methane Production}

As shown in Figure 3, both TBP and total methane production (TMP) showed a decreasing trend from Group A to C, and the average values of Groups A and B were significantly higher than Group C $(p<0.05)$. Therefore, supplying inoculum after hydrolysis and acidification stages could be an effective method for enhancing the organic conversion rate to biogas/methane and relieving the inhibition caused by VFA accumulation. Previous reports showed that the SIR determined the correct operation of the AD process, and an optimum SIR was beneficial to biogas production [37]. In this study, with the same number of substrates, different initial inoculum doses and similar total inoculum doses meant different initial SIRs and similar total SIRs. The results of the study demonstrated that the initial SIR can also affect the $\mathrm{AD}$ process, including biogas/methane production, but the method needed to be further improved. A previous study also found that methane yields increased with the reduction of SIR [26], which might be a reason for the higher methane yield that was achieved in Group B instead of Group C.
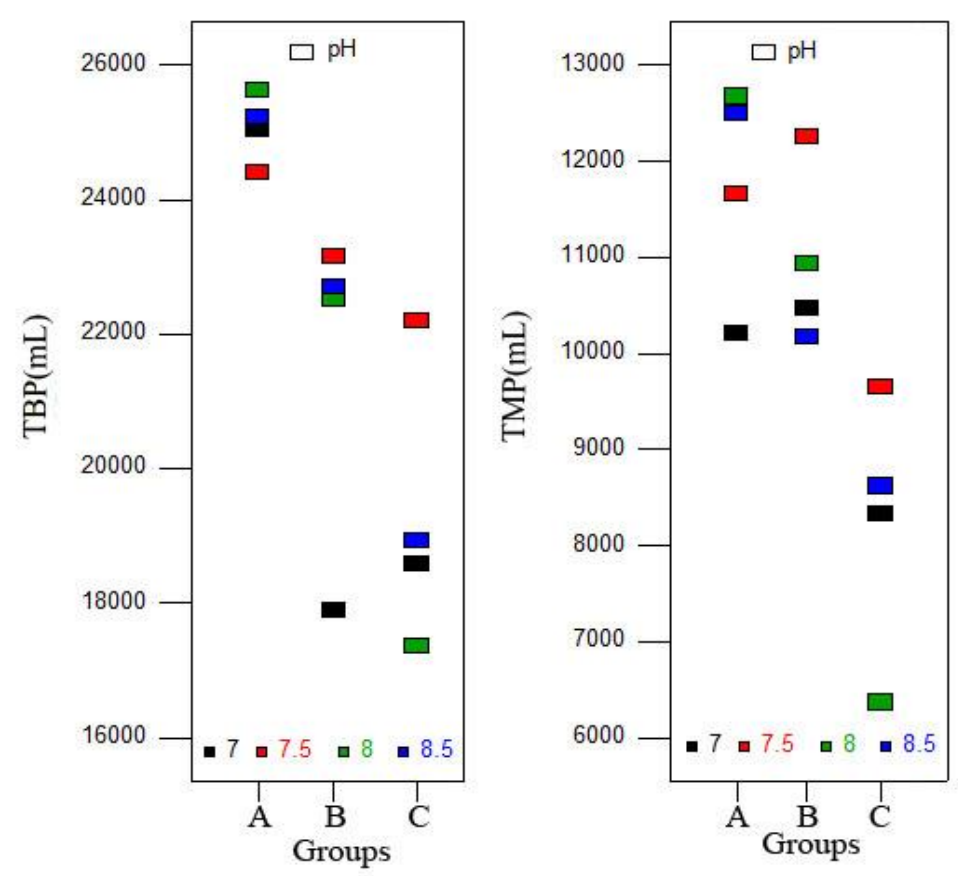

Figure 3. Total biogas production (TBP) and total methane production (TMP) obtained from different groups. 
The highest TBP for Group A was obtained at pH $8.0(25,626 \mathrm{~mL})$, which was significantly higher than others $(p<0.05)$. For Groups B and C, the highest TBPs of 23,156 and 22,203 mL were achieved at $\mathrm{pH} 7.5$, respectively, and were significantly higher than other $\mathrm{pH}(p<0.05)$. The TMP showed a similar trend. The highest VS removal rate was achieved in Group B when $\mathrm{pH}$ was adjusted to 8.5. The reason would be that alkaline digestion conditions $(\mathrm{pH} 8.5)$ improved the hydrolysis rate and substrate conversion to intermediate products, but it also caused inhibition, which inhibited methanogenic activity and decreased methane production [37]. Thus, $\mathrm{pH}$ adjustment ranged from 7.5-8.0 could be the recommended range for codigestion of FW and CM.

\subsection{Lag Phase and Digestion Period}

The predicated lag phase $(\lambda / \mathrm{d})$ obtained from the MGE and digestion period (T/d) are shown in Figure 4. This indicated that methane production was well-fitted by MGE with high fitting coefficients $\mathrm{R}^{2}$ ranging from $0.994-0.999$. The maximum $\lambda$ of $20.5,19.9$, and $19.5 \mathrm{~d}$ were found at $\mathrm{pH} 7.0$ for Group A (Figure 4a) and Group B (Figure 4a), and pH 8.5 for Group C (Figure 4c), respectively, and it was significantly high than other $\mathrm{pH}(p<0.05)$. $\lambda$ was a key parameter used to indicate the ability of microorganisms to adapt to the reaction system, the system recovery time as it began to generate biogas $[1,21]$, and the startup time (the time before stable biogas/methane was produced) of the AD system. Therefore, high inoculum doses in the initial stage (Group C) could enhance the ability of the microorganisms to adapt to the reaction system and recover capacity. Thus, biogas was generated in a shorter time compared to Groups A and B, and the highest TBP was obtained in the initial stage; however, the startup time for the AD system was prolonged because of a high VFA accumulation and a low self-buffering capacity (shown in Figure 2 as the variations of $\mathrm{pH}$ and VFAs). The TBP and TMP at the end of the whole digestion period for all experiments showed no significant differences. Thus, we concluded that inoculum supplements, $\mathrm{pH}$ adjustment, and replacing the liquid supernatant played important roles in improving AD system recovering rate.

The digestion period, $\mathrm{T}_{100 \%}$ (the time for producing the final TBP) and $\mathrm{T}_{90 \%}$ (the time for producing $90 \%$ of TBP) were also calculated (Figure 4). For Group A, the values of $\mathrm{T}_{100 \%}$ ranged from 132 to $163 \mathrm{~d}$, and the maximum value was achieved at $\mathrm{pH} 7.5$, which was significantly higher than others $(p<0.05)$. For Groups B and C, these values ranged from 103 to $120 \mathrm{~d}$ and from 101 to $141 \mathrm{~d}$, respectively, which were lower than Group A. Maximum values were obtained at $\mathrm{pH} 8.0$ and 7.5, respectively. The values obtained for $\mathrm{T}_{90 \%}$ showed the same trend as $\mathrm{T}_{100 \%}$. The main reason was that the high inoculum dose in the initial stage prolonged the lag phase, while the VFA biogas conversion rate, stability, and TBP/TMP showed no significant differences compared to other groups. Therefore, the time to produce the same TBP $\left(\mathrm{T}_{100 \%}\right)$ was prolonged. Comprehensively, it can be concluded that the little amounts of inoculum resulted in higher hydrolysis and acidification rates and a higher biogas/methane production, but it also resulted in a longer lag phase and digestion period. Thus, cost inputs such as energy, economy, and human resources increased. This should be fully considered in practical engineering applications, and further studies are needed. Furthermore, neutral $\mathrm{pH}$ adjustment (7.0) could be a useful method for relieving inhibition, enhancing adaption of microorganisms to digestion conditions, and decreasing the digestion period. 


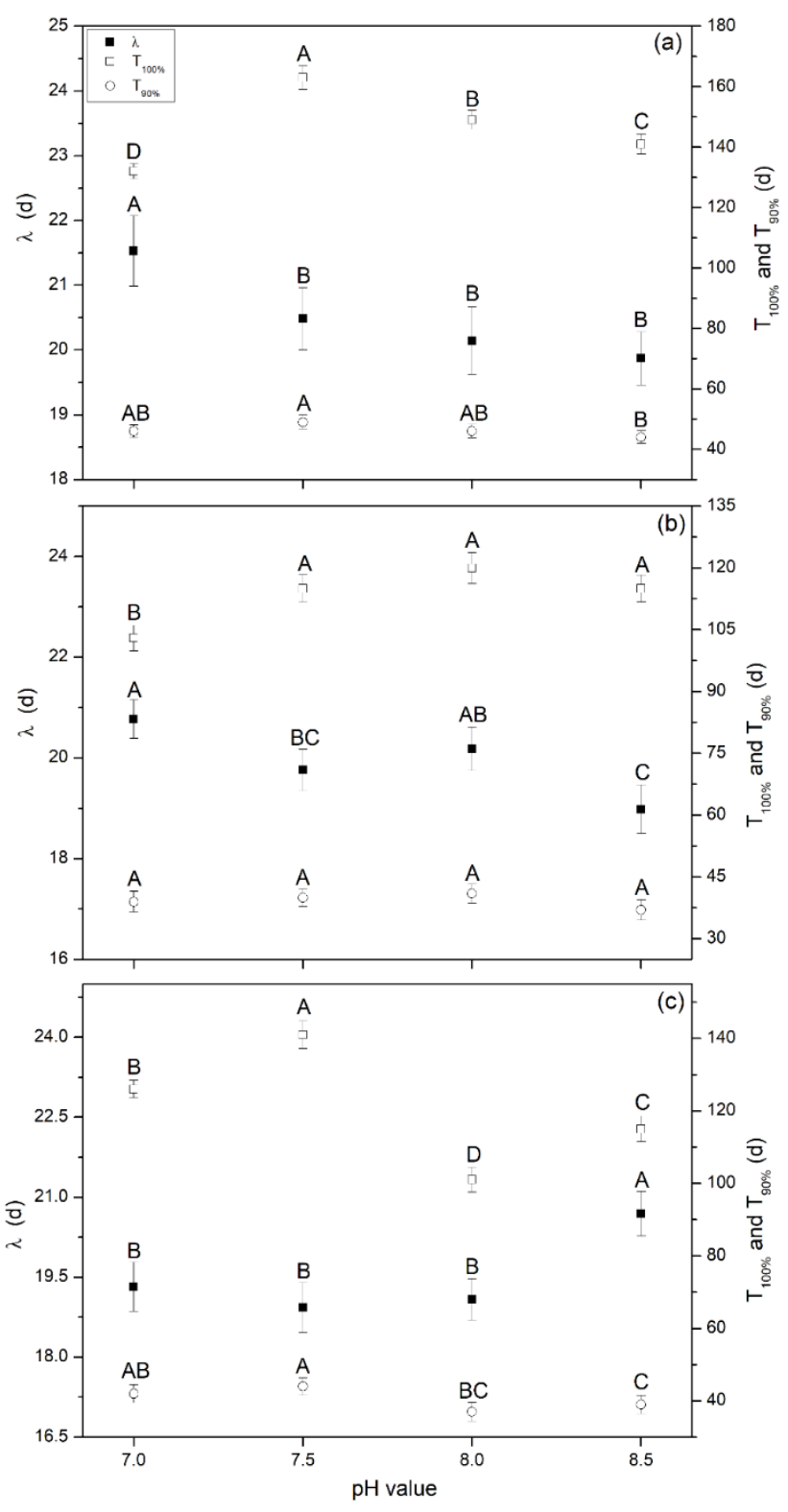

Figure 4. Lag phase and digestion period at different $\mathrm{pH}$ levels obtained from the modified Gompertz model, (a) Group A, (b) Group B, and (c) Group C. Note: $\lambda$ is the lag phase; $\mathrm{T}_{100 \%}$ is the time for producing the TBP; and $\mathrm{T}_{90 \%}$ is the time for producing $90 \%$ of TBP.

\section{Conclusions}

The results showed that this new operating strategy, by controlling temperature, inoculum dose, and $\mathrm{pH}$, and replacing the supernatant liquid at different digestion times based on daily biogas production rates significantly influenced the performance of FW and CM anaerobic codigestion. It was concluded that (1) different initial inoculums in the initial stage affected substrate biodegradability (VFA concentration), which consequently affected the self-buffering capacity and stability (pH). Group A saw higher initial inoculum doses, lower stability, more serious VFA inhibition, and a longer lag phase and digestion period. (2) Inoculum supplementation and $\mathrm{pH}$ adjustment in the second stage played important roles in balancing the $\mathrm{pH}$ of the $\mathrm{AD}$ system and, thus, improving the self-buffering capacity. (3) Liquid supernatant replacement using fresh inoculum showed an efficient positive effect on enhancing system stability, which could be indicated by the final $\mathrm{pH}$, the VFA conversion rate to biogas, VS and COD removal rates, and TBP and TMP with no significant differences between each group. (4) Lower inoculum doses in the initial stage (Groups A and B), adjusting the $\mathrm{pH}$ to 
7.0, and supernatant liquid replacement could significantly improve digestion efficiency. Therefore, adjusting different operational conditions at different stages could be an appropriate method for relieving inhibition. However, for all treatments, the lag phase and digestion period were prolonged, which increased energy input. Therefore, further studies are still needed. The results could offer an important basis for improving treatment efficiency of FW.

Author Contributions: G.-X.R. was the major writer for the first manuscript; N.-N.Z. and C.-L.M. articulated on core arguments and wrote the Introduction and Conclusion sections; X.-J.W., G.-H.Y., Z.-C.L., and B.-R.W. worked on revision and resubmission.

Funding: This work was supported by the basic work of science and technology special project: Natural Science Foundation of Shaanxi Province and Rural Energy Construction Project in 2017; The budget project of the ministry agriculture department (091721301262491003); National Natural Science Foundation of China (51508467); Natural Science Foundation of Province (2016JQ4007); and Postdoctoral Science Foundation of China (2016T90950, 2015M582708).

Acknowledgments: We thank Yanbo Wang and Yanzi Wang who gave important suggestions for improving the manuscript quality.

Conflicts of Interest: The authors declare no conflict of interest.

\section{References}

1. Mehariya, S.; Patel, A.K.; Obulisamy, P.K.; Punniyakotti, E.; Wong, J.W.C. Co-digestion of food waste and sewage sludge for methane production: Current status and perspective. Bioresour. Technol. 2018, 265, 519-531. [CrossRef] [PubMed]

2. Ren, Y.; Yu, M.; Wu, C.; Wang, Q.; Gao, M.; Huang, Q.; Liu, Y. A comprehensive review on food waste anaerobic digestion: Research updates and tendencies. Bioresour. Technol. 2018, 247, 1069-1076. [CrossRef] [PubMed]

3. Arelli, V.; Begum, S.; Anupoju, G.R.; Kuruti, K.; Shailaja, S. Dry anaerobic co-digestion of food waste and cattle manure: Impact of total solids, substrate ratio and thermal pre treatment on methane yield and quality of biomanure. Bioresour. Technol. 2018, 253, 273-280. [CrossRef] [PubMed]

4. Zhang, C.; Su, H.; Baeyens, J.; Tan, T. Reviewing the anaerobic digestion of food waste for biogas production. Renew. Sustain. Energy Rev. 2014, 38, 383-392. [CrossRef]

5. Li, Y.; Zhang, R.; Liu, X.; Chen, C.; Xiao, X.; Feng, L.; He, Y.; Liu, G. Evaluating Methane Production from Anaerobic Mono- and Codigestion of Kitchen Waste, Corn Stover, and Chicken Manure. Energy Fuels 2013, 27, 2085-2091. [CrossRef]

6. Cassendra, P.; Li, Y.; Chew, T.; Ji, J.; Chin, S.; Wai, S. The characterisation and treatment of food waste for improvement of biogas production during anaerobic digestion-A review. J. Clean. Prod. 2018, 172, 1545-1558.

7. Mézes, L.; Bai, A.; Nagy, D.; Cinka, I.; Gabnai, Z. Optimization of Raw Material Composition in an Agricultural Biogas Plant. Trends Renew. Energy 2017, 3, 61-75. [CrossRef]

8. Zhai, N.; Zhang, T.; Yin, D.; Yang, G.; Wang, X.; Ren, G.; Feng, Y. Effect of initial pH on anaerobic co-digestion of kitchen waste and cow manure. Waste Manag. 2015, 38, 126-131. [CrossRef]

9. Ye, J.; Li, D.; Sun, Y.; Wang, G.; Yuan, Z.; Zhen, F.; Wang, Y. Improved biogas production from rice straw by co-digestion with kitchen waste and pig manure. Waste Manag. 2013, 33, 2653-2658. [CrossRef] [PubMed]

10. Zhang, L.; Lee, Y.-W.; Jahng, D. Anaerobic co-digestion of food waste and piggery wastewater: Focusing on the role of trace elements. Bioresour. Technol. 2011, 102, 5048-5059. [CrossRef]

11. Zhao, M.-X.; Ruan, W.-Q. Biogas performance from co-digestion of Taihu algae and kitchen wastes. Energy Convers. Manag. 2013, 75, 21-24. [CrossRef]

12. Kim, J.K.; Oh, B.R.; Chun, Y.N.; Kim, S.W. Effects of temperature and hydraulic retention time on anaerobic digestion of food waste. J. Biosci. Bioeng. 2006, 102, 328-332. [CrossRef]

13. Li, Y.; Jin, Y.; Li, H.; Borrion, A.; Yu, Z.; Li, J. Kinetic studies on organic degradation and its impacts on improving methane production during anaerobic digestion of food waste. Appl. Energy 2018, 213, 136-147. [CrossRef] 
14. Hagos, K.; Zong, J.; Li, D.; Liu, C.; Lu, X. Anaerobic co-digestion process for biogas production: Progress, challenges and perspectives. Renew. Sustain. Energy Rev. 2017, 76, 1485-1496. [CrossRef]

15. Obulisamy, P.K.; Chakraborty, D.; Selvam, A.; Wong, J.W.C. Anaerobic co-digestion of food waste and chemically enhanced primary-treated sludge under mesophilic and thermophilic conditions. Environ. Technol. 2016, 37, 3200-3207. [CrossRef] [PubMed]

16. Siddique, M.N.I.; Wahid, Z.A. Achievements and perspectives of anaerobic co-digestion: A review. J. Clean. Prod. 2018, 194, 359-371. [CrossRef]

17. Lu, X.; Jin, W.; Xue, S.; Wang, X. Effects of waste sources on performance of anaerobic co-digestion of complex organic wastes: Taking food waste as an example. Sci. Rep. 2017, 7, 15702. [CrossRef]

18. Kusch, S.; Schumacher, B.; Oechsner, H.; Schafer, W. Methane yield of oat husks. Biomass Bioenergy 2011, 35 , 2627-2633. [CrossRef]

19. Mao, C.; Wang, X.; Xi, J.; Feng, Y.; Ren, G. Linkage of kinetic parameters with process parameters and operational conditions during anaerobic digestion. Energy 2017, 135, 352-360. [CrossRef]

20. Liao, X.; Zhu, S.; Zhong, D.; Zhu, J.; Liao, L. Anaerobic co-digestion of food waste and landfill leachate in single-phase batch reactors. Waste Manag. 2014, 34, 2278-2284. [CrossRef] [PubMed]

21. Wang, X.; Lu, X.; Li, F.; Yang, G. Effects of temperature and carbon-nitrogen $(\mathrm{C} / \mathrm{N})$ ratio on the performance of anaerobic co-digestion of dairy manure, chicken manure and rice straw: Focusing on ammonia inhibition. PLoS ONE 2014, 9, e97265. [CrossRef]

22. Zhang, T.; Mao, C.; Zhai, N.; Wang, X.; Yang, G. Influence of initial pH on thermophilic anaerobic co-digestion of swine manure and maize stalk. Waste Manag. 2015, 35, 119-126. [CrossRef]

23. Li, Y.; Jin, Y.; Borrion, A.; Li, J. Influence of feed/inoculum ratios and waste cooking oil content on the mesophilic anaerobic digestion of food waste. Waste Manag. 2018, 73, 156-164. [CrossRef]

24. Yin, D.; Liu, W.; Zhai, N.; Wang, Y.; Ren, C.; Yang, G. Regional differentiation of rural household biogas development and related driving factors in China. Renew. Sustain. Energy Rev. 2017, 67, 1008-1018. [CrossRef]

25. Zhou, J.; Zhang, R.; Liu, F.; Yong, X.; Wu, X.; Zheng, T.; Jiang, M.; Jia, H. Biogas production and microbial community shift through neutral $\mathrm{pH}$ control during the anaerobic digestion of pig manure. Bioresour. Technol 2016, 217, 44-49. [CrossRef]

26. Zhang, R.; El-Mashad, H.M.; Hartman, K.; Wang, F.; Liu, G.; Choate, C.; Gamble, P. Characterization of food waste as feedstock for anaerobic digestion. Bioresour. Technol. 2007, 98, 929-935. [CrossRef] [PubMed]

27. Li, L.; Peng, X.; Wang, X.; Wu, D. Anaerobic digestion of food waste: A review focusing on process stability. Bioresour. Technol. 2018, 248 Pt A, 20-28. [CrossRef]

28. Capson-Tojo, G.; Moscoviz, R.; Ruiz, D.; Santa-Catalina, G.; Trably, E.; Rouez, M.; Crest, M.; Steyer, J.P.; Bernet, N.; Delgenes, J.P.; et al. Addition of granular activated carbon and trace elements to favor volatile fatty acid consumption during anaerobic digestion of food waste. Bioresour. Technol. 2018, 260, 157-168. [CrossRef]

29. Yang, Y.Q.; Shen, D.S.; Li, N.; Xu, D.; Long, Y.Y.; Lu, X.Y. Co-digestion of kitchen waste and fruit-vegetable waste by two-phase anaerobic digestion. Environ. Sci. Pollut. Res. Int. 2013, 20, 2162-2171. [CrossRef] [PubMed]

30. González-Fernández, C.; García-Encina, P.A. Impact of substrate to inoculum ratio in anaerobic digestion of swine slurry. Biomass Bioenergy 2009, 33, 1065-1069. [CrossRef]

31. Lee, D.H.; Behera, S.K.; Kim, J.W.; Park, H.S. Methane production potential of leachate generated from Korean food waste recycling facilities: A lab-scale study. Waste Manag. 2009, 29, 876-882. [CrossRef]

32. Zhong, W.; Zhang, Z.; Luo, Y.; Qiao, W.; Xiao, M.; Zhang, M. Biogas productivity by co-digesting Taihu blue algae with corn straw as an external carbon source. Bioresour. Technol. 2012, 114, 281-286. [CrossRef] [PubMed]

33. Yuan, X.; Shi, X.; Zhang, D.; Qiu, Y.; Guo, R.; Wang, L. Biogas production and microcystin biodegradation in anaerobic digestion of blue algae. Energy Environ. Sci. 2011, 4, 1511. [CrossRef]

34. Misi, S.N.; Forster, C.F. Batch Co-Digestion of Two-Component Mixtures of Agro-Wastes. Process Saf. Environ. Prot. 2001, 79, 365-371. [CrossRef]

35. Wang, Y.; Zang, B.; Li, G.; Liu, Y. Evaluation the anaerobic hydrolysis acidification stage of kitchen waste by pH regulation. Waste Manag. 2016, 53, 62-67. [CrossRef] 
36. Elreedy, A.; Fujii, M.; Tawfik, A. Factors affecting on hythane bio-generation via anaerobic digestion of mono-ethylene glycol contaminated wastewater: Inoculum-to-substrate ratio, nitrogen-to-phosphorus ratio and pH. Bioresour. Technol. 2017, 223, 10-19. [CrossRef] [PubMed]

37. Montañés, R.; Pérez, M.; Solera, R. Anaerobic mesophilic co-digestion of sewage sludge and sugar beet pulp lixiviation in batch reactors: Effect of pH control. Chem. Eng. J. 2014, 255, 492-499. [CrossRef]

(C) 2019 by the authors. Licensee MDPI, Basel, Switzerland. This article is an open access article distributed under the terms and conditions of the Creative Commons Attribution (CC BY) license (http://creativecommons.org/licenses/by/4.0/). 